\title{
Chronic kidney disease and risk of major cardiovascular disease and non-vascular mortality: prospective population based cohort study
}

\author{
Emanuele Di Angelantonio, university lecturer, ${ }^{1}$ Rajiv Chowdhury, research associate, ${ }^{1}$ Nadeem Sarwar, \\ university lecturer, ${ }^{1,2}$ Thor Aspelund, senior statistician, ${ }^{3,4}$ John Danesh, professor, ${ }^{1}$ Vilmundur Gudnason, \\ professor 3.4
}

${ }^{1}$ Department of Public Health and Primary Care, University of Cambridge, Cambridge CB1 8RN, UK

${ }^{2}$ Section of Population Health Sciences, University of Aberdeen, Aberdeen, UK

${ }^{3}$ Icelandic Heart Association, Kopavogur, Iceland

${ }^{4}$ University of Iceland, Reykjavík, Iceland

Correspondence to:

E Di Angelantonio

emanuele.diangelantonio@phpc. cam.ac.uk

Cite this as: $B M J$ J 2010;341:C4986 doi:10.1136/bmj.c4986

\section{ABSTRACT}

Objective To quantify associations of chronic kidney disease stages with major cardiovascular disease and non-vascular mortality in the general adult population. Design Prospective population based cohort study. Setting Reykjavik, Iceland.

Participants 16958 people aged 33-81 years without manifest vascular disease and with available information on stage of chronic kidney disease (defined by both estimated glomerular filtration rate and urinary protein) at study entry.

Main outcome measures Hazard ratios for time to major coronary heart disease outcomes and mortality. Results 1210 (7\%) of participants had chronic kidney disease at entry. During a median follow-up of 24 years, 4010 coronary heart disease outcomes, 559 deaths from stroke, and 3875 deaths from non-vascular causes were recorded. Compared with the reference group (estimated glomerular filtration rate $75-89 \mathrm{ml} / \mathrm{min} / 1.73 \mathrm{~m}^{2}$ and no proteinuria), people with lower renal function within the normal range of glomerular filtration rate did not have significantly higher risk of coronary heart disease. By contrast, in 1210 (7\%) participants with chronic kidney disease at entry, hazard ratios for coronary heart disease, adjusted for several conventional cardiovascular risk factors, were 1.55 (95\% confidence interval 1.02 to 2.35 ) for stage $1,1.72$ (1.30 to 2.24) for stage 2, 1.39 (1.22 to 1.58) for stage $3 a, 1.90$ (1.22 to 2.96$)$ for stage $3 b$, and 4.29 (1.78 to 10.32 ) for stage 4 . Information on chronic kidney disease increased discrimination and reclassification indices for coronary heart disease when added to conventional risk factors ( $\mathrm{P}<0.01)$. The incremental gain provided by chronic kidney disease was lower than that provided by diabetes or smoking ( $\mathrm{C}$ index increases of $0.0015,0.0024$, and 0.0124 respectively). Hazard ratios with chronic kidney disease were 0.97 (0.82 to 1.15$)$ for cancer mortality and 1.26 (1.07 to 1.50$)$ for other non-vascular mortality.

Conclusions In people without manifest vascular disease, even the earliest stages of chronic kidney disease are associated with excess risk of subsequent coronary heart disease. Assessment of chronic kidney disease in addition to conventional risk factors modestly improves prediction of risk for coronary heart disease in this population. Further studies are needed to investigate associations between chronic kidney disease and nonvascular mortality from causes other than cancer.

\section{INTRODUCTION}

End stage renal failure is known to be associated with striking excesses of cardiovascular and all cause mortality. ${ }^{1}$ Strong associations have also been reported between non-dialysis dependent chronic kidney disease and such outcomes in patients with ischaemic cardiovascular diseases, heart failure, and high blood pressure. ${ }^{2-4}$ Such observations have led to recommendations by scientific and professional bodies that patients with manifest cardiovascular disease should be screened for evidence of kidney disease and that patients with chronic kidney disease should be regarded as at very high risk of coronary heart disease. ${ }^{56}$ In the general adult population, however, chronic kidney disease often goes undiagnosed because it is largely asymptomatic. ${ }^{7}$ Several population based prospective studies have reported on associations between renal function and vascular disease..$^{8-15}$ However, many such studies have lacked concomitant assessment of estimated glomerular filtration rate and urinary protein status or involved less than 10 years of follow-up (the time horizon used in most clinical cardiovascular risk scores), omitted measures of discrimination or reclassification of risk to help in judging the incremental predictive value of assessing chronic kidney disease, or involved some combination of these limitations. Hence, determining the potential value of assessment of chronic kidney disease in population-wide cardiovascular disease screening programmes, such as the National Health Service health check in the United Kingdom, ${ }^{16}$ has been difficult.

We report on the incremental value of assessment of chronic kidney disease for prediction of risk for coronary heart disease in a population based prospective study of people without manifest vascular disease who have been monitored, on average, for almost a 
quarter of a century. To assist in interpretation, we have compared the predictive ability of chronic kidney disease with that of smoking and diabetes.

\section{METHODS}

Participants, measurements, and end points

The Reykjavik study has been described in detail previously. ${ }^{17}$ Briefly, all men born between 1907 and 1934 and all women born between 1908 and 1935 who were resident in Reykjavik, Iceland, and its adjacent communities on 1 December 1966 were identified in the national population register and then invited to participate in the Reykjavik study during five stages of recruitment between 1967 and 1991, yielding a total of 9134 male and 9769 female participants (72\% response rate). All participants gave informed consent. Nurses administered questionnaires, made physical measurements, recorded an electrocardiogram, and collected urine and fasting venous blood samples at baseline. Creatinine measurements were made at baseline within days of the initial examination by using the Jaffe method. ${ }^{18}$ Values of estimated glomerular filtration rate were calculated with the four variable modification of diet in renal disease $\left(\mathrm{MDRD}^{19}\right)$ prediction equation and expressed as $\mathrm{ml} / \mathrm{min} / 1.73 \mathrm{~m}^{2}$ (with subsidiary analyses using estimated glomerular filtration rate calculated with the Chronic Kidney Disease Epidemiology Collaboration (CKD-EPI ${ }^{20}$ ) equation). Serum creatinine concentrations could not be recalibrated to the more accurate isotope dilution mass spectrometry standard. Presence of proteinuria was assessed at baseline with a urinary dipstick (Bayer Diagnostics Ames Multistix or Boehringer Mannheim Multistix). Results were considered positive if the dipstick test was $1+$ or greater. Other analytes were measured by using standard methods, as described previously. ${ }^{21}$ As high density lipoprotein cholesterol concentrations were available for only a small subset of participants, Framingham based models were not used.

All participants have been monitored by central registries for occurrence of non-fatal myocardial infarction (on the basis of multinational monitoring of trends and determinants in cardiovascular disease (MONICA) or similar criteria) or coronary revascularisation (coronary artery bypass grafting or

\begin{tabular}{|c|c|c|}
\hline Stage & $\begin{array}{l}\text { Glomerular filtration rate } \\
\quad(\mathrm{ml} / \mathrm{min} / 1.73 \mathrm{~m} 2)\end{array}$ & Description \\
\hline 1 & $\geq 90$ & $\begin{array}{l}\text { Normal or increased glomerular filtration rate, with other evidence of } \\
\text { kidney damage* }\end{array}$ \\
\hline 2 & $60-89$ & $\begin{array}{l}\text { Slight decrease in glomerular filtration rate, with other evidence of kidney } \\
\text { damage* }\end{array}$ \\
\hline $3 a$ & $45-59$ & \multirow{2}{*}{$\begin{array}{l}\text { Moderate decrease in glomerular filtration rate, with or without other } \\
\text { evidence of kidney damage* }\end{array}$} \\
\hline $3 b$ & $30-44$ & \\
\hline 4 & $15-29$ & $\begin{array}{l}\text { Severe decrease in glomerular filtration rate, with or without other } \\
\text { evidence of kidney damage* }\end{array}$ \\
\hline 5 & $\ll 15$ & Established renal failure \\
\hline
\end{tabular}

*Evidence of kidney damage defined in this analysis as evidence of proteinuria assessed with urinary dipstick. percutaneous transluminal coronary angioplasty) until the end of 2005 and cause specific mortality (on the basis of a death certificate with international classification of diseases (ICD) codes) until the end of $2007 .^{22}$ Loss to follow-up has been about $0.6 \%$ to date. Cause specific mortality was coded according to ICD-9 up to December 1996 and ICD-10 subsequently (web table A). Compared with a previous report in a subset of participants, ${ }^{23}$ this study used cohort-wide data on both estimated glomerular filtration rate and proteinuria, as well as extended follow-up.

\section{Statistical analysis}

Principal analyses excluded participants with a history of cardiovascular disease at entry (defined as coronary heart disease, stroke, other heart diseases (such as angina or valvular disease), or coronary revascularisation) or known to be receiving renal replacement treatment. Subsidiary analyses also excluded participants with self reported diabetes mellitus or fasting blood glucose of $7 \mathrm{mmol} / \mathrm{l}$ or above at entry. We defined chronic kidney disease as either presence of proteinuria or estimated glomerular filtration rate $<60 \mathrm{ml} /$ $\mathrm{min} / 1.73 \mathrm{~m}^{2}$, following the guidelines from the UK National Institute for Health and Clinical Excellence (NICE) (table 1) or, in subsidiary analyses, the Kidney Disease Outcomes Quality Initiative criteria. ${ }^{2425} \mathrm{We}$ classified participants without chronic kidney disease (estimated glomerular filtration rate $\geq 60 \mathrm{ml} / \mathrm{min} / 1.73$ $\mathrm{m}^{2}$ and absence of proteinuria) into three groups on the basis of thresholds of estimated glomerular filtration rate used in a previous study: 60-74, 75-89, and $\geq 90 \mathrm{ml} / \mathrm{min} / 1.73 \mathrm{~m}^{2} .{ }^{13}$

The principal outcome was coronary heart disease, defined as non-fatal or fatal myocardial infarction or coronary revascularisation. We restricted analyses to participants with complete information on relevant covariates. Participants contributed only their first non-fatal coronary heart disease outcomes or death (that is, we did not include deaths preceded by nonfatal myocardial infarction or coronary revascularisation). We calculated hazard ratios by using Cox proportional models stratified by sex, using floating risks. ${ }^{26}$ Subsidiary analyses investigated the shape of associations by dividing the data into fifths of baseline values of estimated glomerular filtration rate, with further subdivision of the lowest fifth into three more groups, and using regression spline methods. To assess the prediction of risk for coronary heart disease with chronic kidney disease in addition to several conventional risk factors (age, sex, smoking, history of diabetes, systolic blood pressure, and total cholesterol), we calculated measures of discrimination for censored time to event data (Harrell's C index) and reclassification (net reclassification improvement and integrated discrimination index using 10 year risk categories of 0 $5 \%, 5-10 \%, 10-20 \%$, and $\geq 20 \%) .{ }^{27}$ We compared the predictive gain provided by assessment of chronic kidney disease against that provided by information on diabetes and smoking status, removing each of these variables from a risk model containing several 
Table 2 |Demographic and clinical baseline characteristics by chronic kidney disease (CKD) status. Values are numbers (percentages) unless stated otherwise

\begin{tabular}{|c|c|c|c|c|}
\hline Characteristics & Overall population ( $\mathrm{n}=16958$ ) & Non-CKD ( $n=15748)$ & CKD $(n=1210)$ & $P$ value \\
\hline \multicolumn{5}{|l|}{ Demographic factors } \\
\hline Mean (SD) age (years) & $52.5(8.6)$ & $51.9(8.3)$ & $59.4(9.8)$ & $<0.001$ \\
\hline Male sex & $8237(48.6)$ & $7848(49.8)$ & $389(32.1)$ & $<0.001$ \\
\hline \multicolumn{5}{|l|}{ Established risk factors } \\
\hline Current cigarette smokers & $8013(47.3)$ & $7570(48.1)$ & $443(36.6)$ & $<0.001$ \\
\hline History of diabetes & $400(2.4)$ & $351(2.2)$ & $49(4.0)$ & $<0.001$ \\
\hline Mean (SD) systolic blood pressure (mm Hg) & $138(22)(n=16957)$ & $138(21)(n=15747)$ & $145(25)$ & $<0.001$ \\
\hline Mean (SD) diastolic blood pressure (mm Hg) & $87(12)(n=16956)$ & $86(12)(n=15746)$ & $88(13)$ & $<0.001$ \\
\hline Mean (SD) body mass index $\left(\mathrm{kg} / \mathrm{m}^{2}\right)$ & $25.4(3.9)(n=16895)$ & $25.3(3.8)(n=15696)$ & $26.3(4.4)(n=1199)$ & $<0.001$ \\
\hline \multicolumn{5}{|l|}{ Blood based factors } \\
\hline Mean (SD) total cholesterol (mmol/l) & $6.48(1.16)(n=16942)$ & $6.46(1.15)(n=15734)$ & $6.74(1.28)(n=1208)$ & $<0.001$ \\
\hline Mean (SD) log triglycerides (mmol/l) & $0.02(0.45)(n=16447)$ & $0.01(0.44)(n=15263)$ & $0.16(0.45)(n=1184)$ & $<0.001$ \\
\hline Mean (SD) fasting glucose (mmol/l) & $4.48(0.74)(n=16905)$ & $4.47(0.70)(n=15698)$ & $4.57(1.08)(n=1207)$ & $<0.001$ \\
\hline $\begin{array}{l}\text { Mean }(\mathrm{SD}) \text { log erythrocyte sedimentation } \\
\text { rate }(\mathrm{mm} / \mathrm{h})\end{array}$ & $1.90(0.94)(n=16066)$ & $1.88(0.93)(n=14916)$ & $2.13(0.97)(n=1150)$ & $<0.001$ \\
\hline \multicolumn{5}{|l|}{ Socioeconomic factors } \\
\hline Non-manual occupation & $5841 / 10889(53.6)$ & $5441 / 10260(53.0)$ & $400 / 629(63.6)$ & $<0.001$ \\
\hline Education beyond high school & $2558(15.1)$ & $2394(15.2)$ & $164(13.6)$ & 0.123 \\
\hline \multicolumn{5}{|l|}{ Renal markers } \\
\hline Mean (SD) creatinine (mg/dl) & $0.95(0.18)$ & $0.93(0.15)$ & $1.17(0.33)$ & $<0.001$ \\
\hline Mean (SD) eGFR (MDRD equation) & $78.7(14.4)$ & $80.2(13.2)$ & $58.7(14.8)$ & $<0.001$ \\
\hline Positive urine protein & $241(1.4)$ & 0 & $241(19.9)$ & $<0.001$ \\
\hline
\end{tabular}

eGFR=estimated glomerular filtration rate; MDRD=modification of diet for renal disease.

16369 participants had complete information on smoking status, history of diabetes, total cholesterol, triglycerides, systolic blood pressure, and body mass index.

conventional risk factors plus chronic kidney disease. We used Stata version 11 for statistical analyses, with two sided tests and $\mathrm{P}<0.05$.

\section{RESULTS}

\section{Baseline associations}

The mean age of the 16958 participants was 53 (range 33-81; SD 9) years, $51 \%$ were female, and the mean estimated glomerular filtration rate was $79(14) \mathrm{ml} /$ $\min / 1.73 \mathrm{~m}^{2}$ (table 2 ). Six per cent (1016) of participants had an estimated glomerular filtration rate below $60,1.4 \%$ (241) had proteinuria, and 7\% (1210) had chronic kidney disease at entry (65 had stage 1, 129 had stage 2, 939 had stage 3a, 65 had stage 3b, and 12 had stage 4). People with chronic kidney disease had higher mean levels of cardiovascular risk factors than did people without chronic kidney disease, except for smoking and male sex (table 2, web table B). During 383553 person years at risk (median follow-up 24 (interquartile range 17-31) years), 4010 coronary heart disease outcomes, 559 deaths from stroke, 662 deaths from other vascular causes, and 3875 deaths from non-vascular causes were recorded.

\section{Hazard ratios with disease outcomes}

Compared with the reference group (estimated glomerular filtration rate of $75-89 \mathrm{ml} / \mathrm{min} / 1.73 \mathrm{~m}^{2}$ and without proteinuria), people at each clinically defined stage of chronic kidney disease had higher risk of coronary heart disease (fig 1 , table 3 , web table C). This relation was non-linear in shape, and the possibility existed of a weakly positive hazard ratio in people with out chronic kidney disease who had an estimated glomerular filtration rate of $90 \mathrm{ml} / \mathrm{min} / 1.73 \mathrm{~m}^{2}$ or above. Regression spline analyses yielded broadly similar findings (web fig A). In analyses comparing people with and without chronic kidney disease, the hazard ratio for coronary heart disease was 1.53 (95\% confidence interval 1.36 to 1.71 ) after adjustment for age and sex only; it was 1.45 (1.29 to 1.62) after further adjustment for smoking status, history of diabetes, systolic blood pressure, body mass index, total cholesterol, and triglycerides ("further adjustment"). In analyses comparing people with and without proteinuria, the hazard ratio for coronary heart disease was 1.96 (1.60 to 2.40 ) after adjustment for age and sex only and 1.72 (1.40 to 2.11) after further adjustment. The hazard ratio for coronary heart disease with chronic kidney disease was possibly higher in people with diabetes, but it did not vary considerably by other risk factors recorded (web fig B). After further adjustment, hazard ratios with chronic kidney disease were 1.21 (0.75 to 1.95$)$ for ischaemic stroke, 1.18 (0.77 to 1.80$)$ for unclassified stroke, 1.02 (0.55 to 1.89) for haemorrhagic stroke, 0.71 (0.37 to 1.33) for other deaths attributed to cerebrovascular disease, and 1.22 (0.89 to 1.66) for other deaths from vascular disease (mainly heart failure, cardiac arrhythmia, and pulmonary embolism) (fig 2).

Associations between different stages of chronic kidney disease and the aggregate of non-vascular mortality were non-linear (fig 1, web fig A). Again, the 

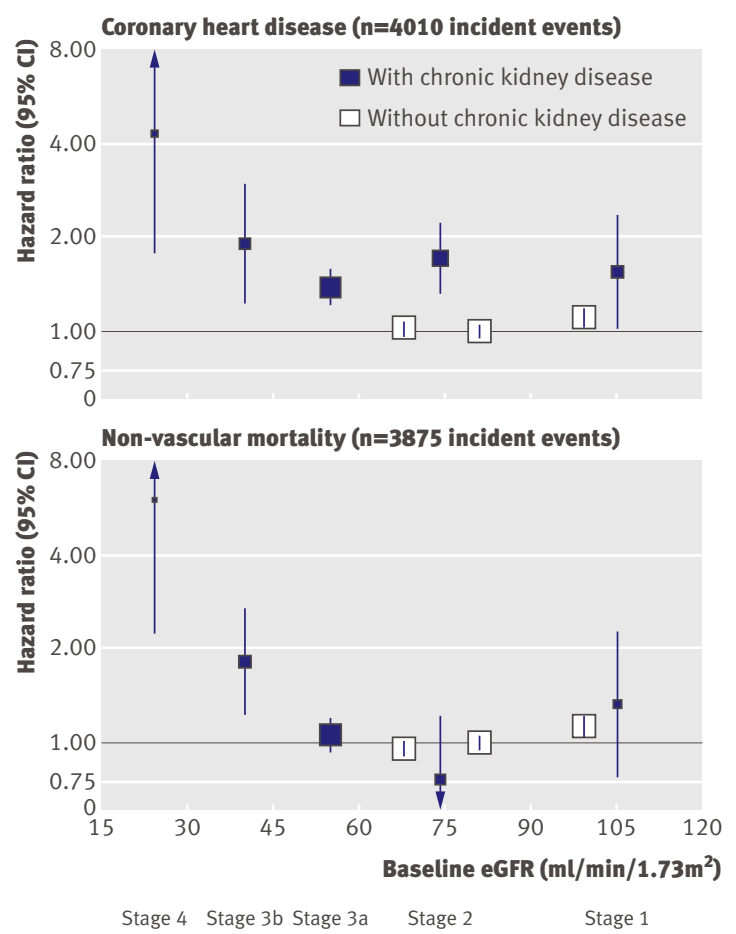

Fig 1| Renal function and risk of coronary heart disease and non-vascular mortality. Hazard ratios are adjusted for age, sex, smoking status, history of diabetes, total cholesterol, log triglycerides, systolic blood pressure, and body mass index. All hazard ratios are compared with people without chronic kidney disease with estimated glomerular filtration rate (eGFR) of $75-89 \mathrm{ml} / \mathrm{min} / 1.73 \mathrm{~m}^{2}$ and plotted against mean eGFR within each group. Size of data markers is proportional to inverse of variance of hazard ratios. Confidence intervals are calculated using floating variances; eGFR is calculated using MDRD equation

possibility existed of a weakly positive hazard ratio in people without chronic kidney disease who had an estimated glomerular filtration rate of $90 \mathrm{ml} / \mathrm{min} / 1.73 \mathrm{~m}^{2}$ or above. In contrast with the findings for coronary heart disease, however, only people with stage $3 \mathrm{~b}$ or stage 4 chronic kidney disease had a higher risk of non-vascular mortality compared with the reference group (fig 1, table 3). Hazard ratios were 0.97 (0.82 to 1.15$)$ for mortality due to cancer and 1.26 (1.07 to 1.50) for mortality not attributed to cancer or vascular disease, including deaths from renal failure (fig 2).

We found qualitatively similar findings to those reported here in analyses that used Kidney Disease Outcomes Quality Initiative criteria (web table D), ${ }^{25}$ used the CKD-EPI equation (web table E), used a competing risks model (web table F), ${ }^{28}$ compared subtypes of coronary heart disease (fig 2), excluded the initial five years of follow-up (web fig C), and considered the impact of undiagnosed new onset chronic kidney disease (web fig D). Too few deaths from non-vascular causes were available to allow us to subdivide outcomes further. Similar considerations apply to the small numbers of people who had proteinuria in chronic kidney disease stages 3 and 4 .

\section{Chronic kidney disease and coronary heart disease risk prediction}

Addition of smoking status, systolic blood pressure, total cholesterol, and diabetes to a coronary heart disease risk model containing only age (and stratified by sex) increased the $\mathrm{C}$ index from 0.6453 to 0.6963 . Further addition of information on chronic kidney disease status increased the $\mathrm{C}$ index from 0.6963 to 0.6978 , an increase of $0.0015(0.0004$ to 0.0026 ; $\mathrm{P}=0.010)$ denoting correct prediction of the order of coronary heart disease outcomes in a further 15 out of 10000 pairs of participants screened. Addition of information on chronic kidney disease status to the risk factors listed above appropriately reclassified $5.3 \%$ of participants who developed coronary heart disease and $2.0 \%$ of participants who did not (web table $\mathrm{G}$ ).

Table $3 \mid$ Association of renal function with coronary heart disease and non-vascular mortality

\begin{tabular}{|c|c|c|c|c|c|c|c|}
\hline \multirow[b]{2}{*}{ Renal function } & \multirow[b]{2}{*}{ No } & \multicolumn{3}{|c|}{ Coronary heart disease } & \multicolumn{3}{|c|}{ Non-vascular mortality } \\
\hline & & $\begin{array}{l}\text { No of } \\
\text { events }\end{array}$ & Age and sex adjusted & Further adjusted* & $\begin{array}{l}\text { No of } \\
\text { events }\end{array}$ & Age and sex adjusted & Further adjusted* \\
\hline \multicolumn{8}{|l|}{ Participants without chronic kidney disease } \\
\hline $\mathrm{eGFR} \geq 90 \mathrm{ml} / \mathrm{min} / 1.73 \mathrm{~m}^{2} \dagger$ & 3265 & 872 & $1.09(1.02$ to 1.17$)$ & $1.11(1.03$ to 1.19$)$ & 803 & 1.15 (1.07 to 1.24$)$ & $1.13(1.05$ to 1.21$)$ \\
\hline eGFR $75-89 \mathrm{ml} / \mathrm{min} / 1.73 \mathrm{~m}^{2}$ & 6031 & 1478 & $1.00(0.95$ to 1.05$)$ & $1.00(0.95$ to 1.06$)$ & 1404 & $1.00(0.95$ to 1.06$)$ & $1.00(0.95$ to 1.06$)$ \\
\hline eGFR $60-74 \mathrm{ml} / \mathrm{min} / 1.73 \mathrm{~m}^{2} \dagger$ & 5902 & 1319 & 1.04 (0.99 to 1.10$)$ & 1.02 (0.97 to 1.08$)$ & 1346 & 0.94 (0.89 to 0.99$)$ & 0.95 (0.90 to 1.00$)$ \\
\hline \multicolumn{8}{|l|}{ Participants with chronic kidney disease } \\
\hline $\begin{array}{l}\text { Stage } 1 \text { (eGFR } \geq 90 \mathrm{ml} / \mathrm{min} / 1.73 \mathrm{~m}^{2} \text { plus } \\
\text { proteinuria) } \dagger\end{array}$ & 63 & 22 & 1.77 (1.16 to 2.69$)$ & 1.55 (1.02 to 2.35$)$ & 13 & 1.37 (0.79 to 2.36$)$ & $1.33(0.77$ to 2.29$)$ \\
\hline $\begin{array}{l}\text { Stage } 2 \text { (eGFR } 60-89 \mathrm{ml} / \mathrm{min} / 1.73 \mathrm{~m}^{2} \text { plus } \\
\text { proteinuria) }\end{array}$ & 125 & 54 & 1.94 (1.49 to 2.54$)$ & $1.72(1.30$ to 2.24$)$ & 21 & $0.83(0.54$ to 1.27$)$ & $0.76(0.50$ to 1.17$)$ \\
\hline Stage 3a (eGFR $\left.45-59 \mathrm{ml} / \mathrm{min} / 1.73 \mathrm{~m}^{2}\right) \dagger$ & 908 & 240 & 1.44 (1.26 to 1.64$)$ & $1.39(1.22$ to 1.58$)$ & 258 & $1.03(0.90$ to 1.16$)$ & 1.06 (0.94 to 1.21$)$ \\
\hline Stage 3b (eGFR $\left.30-44 \mathrm{ml} / \mathrm{min} / 1.73 \mathrm{~m}^{2}\right) \dagger$ & 63 & 20 & 2.26 (1.45 to 3.51$)$ & $1.90(1.22$ to 2.96$)$ & 26 & 1.81 (1.23 to 2.67$)$ & $1.82(1.24$ to 2.68$)$ \\
\hline Stage 4 (eGFR $\left.15-29 \mathrm{ml} / \mathrm{min} / 1.73 \mathrm{~m}^{2}\right) \dagger$ & 12 & 5 & $6.46(2.69$ to 15.5$)$ & $4.29(1.78$ to 10.3$)$ & 4 & $6.40(2.40$ to 17.1$)$ & $5.97(2.24$ to 15.9$)$ \\
\hline
\end{tabular}

eGFR=estimated glomerular filtration rate.

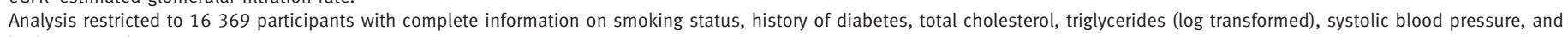
body mass index.

*Additionally adjusted for smoking status, history of diabetes, total cholesterol, triglycerides (log transformed), systolic blood pressure, and body mass index.

†Reference group=people with eGFR $75-89 \mathrm{ml} / \mathrm{min} / \mathrm{m}^{2}$ and no proteinuria.

fNo participants in this cohort were in stage 5 or kidney failure stage (that is, eGFR $<15 \mathrm{ml} / \mathrm{min} / 1.73 \mathrm{~m}^{2}$ ). 


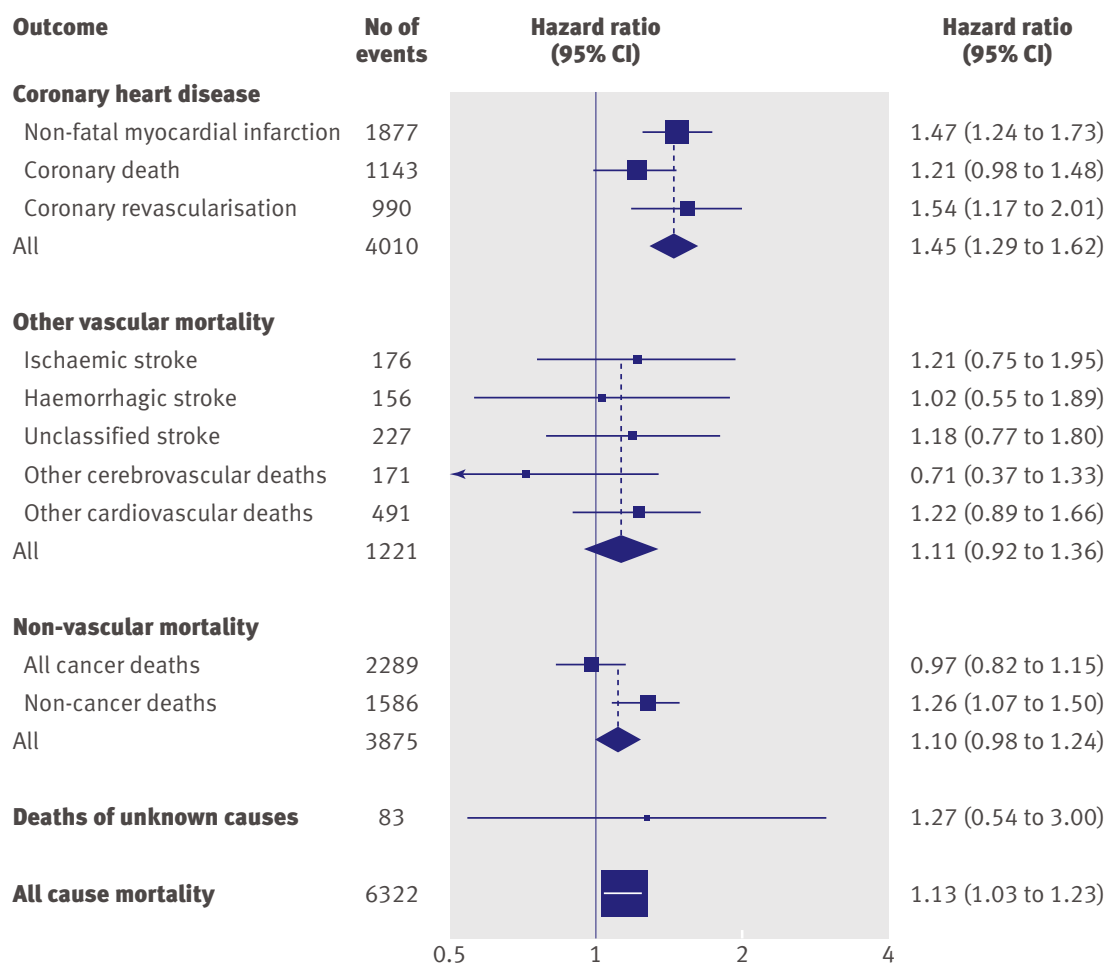

Fig 2 | Risk of vascular and non-vascular outcomes in people with chronic kidney disease compared with people without chronic kidney disease. Analysis restricted to participants with complete information on smoking status, history of diabetes, total cholesterol, triglycerides (log transformed), systolic blood pressure, and body mass index. Hazard ratios are adjusted for age, sex, smoking status, history of diabetes, systolic blood pressure, total cholesterol, log triglycerides, and body mass index. Size of data markers is proportional to inverse of variances of hazard ratios

After we took inappropriate reclassification into account, however, the overall net reclassification improvement was $1.04 \%(-0.93 \%$ to $3.02 \% ; \mathrm{P}=0.301)$. When we calculated the average absolute improvement in prediction of risk without categorisation into risk groups, the integrated improvement in discrimination was 0.0022 (0.0010 to $0.0033 ; \mathrm{P}<0.001)$. This denotes an improvement equivalent to about $0.2 \%$ in predicted absolute risk for a typical screened person on addition of information on chronic kidney disease status to other risk factors.

Compared with a model containing several conventional risk factors plus chronic kidney disease status, the $\mathrm{C}$ index decreased by $0.0015(\mathrm{P}=0.010)$ after removal of chronic kidney disease, by 0.0024

Table 4 |Change in metrics of coronary heart disease risk prediction on removal of chronic kidney disease, history of diabetes, or smoking status from a model containing other conventional risk factors

\begin{tabular}{lccc} 
& Discrimination: decrease in C & \multicolumn{2}{c}{ Reclassification } \\
\cline { 3 - 4 } Factor omitted & index (P value) & IDI (P value) & \% NRI (P value) \\
Chronic kidney disease & $0.0015(0.010)$ & $0.0022(\nless 0.001)$ & $1.04(0.301)$ \\
\hline History of diabetes & $0.0024(0.002)$ & $0.0016(0.017)$ & $2.34(0.003)$ \\
\hline Smoking status & $0.0124(<0.001)$ & $0.0063(<0.001)$ & $6.77(<0.001)$ \\
\hline
\end{tabular}

Full model with conventional risk factors (stratified by sex) includes age, smoking status (current $v$ other), history of diabetes (yes $v$ no), total cholesterol, systolic blood pressure, and chronic kidney disease (yes $v$ no). $\mid \mathrm{DI}=$ =integrated discrimination index; NRI=net reclassification improvement.
$(\mathrm{P}=0.002)$ after removal of diabetes, and by 0.0124 $(\mathrm{P}<0.001)$ after removal of smoking status (table 4$)$. The decrease in the integrated discrimination improvement score was $0.0022(\mathrm{P}<0.001)$ after removal of chronic kidney disease, $0.0016(\mathrm{P}=0.017)$ after removal of diabetes, and $0.0063(\mathrm{P}<0.001)$ after removal of smoking status. The corresponding decrease in the net reclassification improvement was $1.04 \%(\mathrm{P}=0.30)$ after removal of chronic kidney disease, $2.34 \%(\mathrm{P}=0.003)$ after removal of diabetes, and $6.77 \%(\mathrm{P}<0.001)$ after removal of smoking status. The incremental value of information on chronic kidney disease status was lower when added to more elaborate risk prediction models that used information on additional risk factors.

\section{DISCUSSION}

For people without manifest vascular disease, we have shown that even the earliest stages of chronic kidney disease are associated with higher risk of coronary heart disease. In people without clinically defined chronic kidney disease, however, lower estimated glomerular filtration rate was not significantly associated with risk of coronary heart disease. Hence, in contrast with blood pressure and total cholesterol, which each have log-linear relations with risk of coronary heart disease across their range of values, ${ }^{29}$ estimated glomerular filtration rate seems to be non-linearly related to risk of coronary heart disease. The risk threshold for estimated glomerular filtration rate seems to be near to $60 \mathrm{ml} / \mathrm{min} / 1.73 \mathrm{~m}^{2}$, or the value that clinically defines chronic kidney disease. The lack of an appreciable change in associations in analyses that excluded people with diabetes at entry, omitted initial follow-up, or adjusted for several cardiovascular risk factors suggests that our results are robust. However, although plausible mechanisms have been proposed to suggest that impaired kidney function may itself be a causal factor in coronary heart disease ${ }^{30}$ the possibility remains that chronic kidney disease is chiefly a marker of unfavourable cardiovascular risk profiles. We also found that advanced stages of chronic kidney disease were significantly associated with the aggregate of non-vascular mortality, particularly deaths not attributed to cancer (including, unsurprisingly, those related to end stage renal disease itself $\left.{ }^{14}\right)$.

Our other main finding is that assessment of chronic kidney disease status in a general middle aged population only modestly improves prediction of risk for coronary heart disease when information is available on conventional cardiovascular risk factors. For example, the clinically relevant incremental gain provided by chronic kidney disease was about half that provided by history of diabetes and about a sixth that provided by history of smoking. Hence, although assessment of chronic kidney disease is potentially practicable on a population-wide basis (as it involves relatively simple blood and urine tests), further studies in other populations are needed to determine whether its use for screening for cardiovascular disease would be sufficiently informative to justify the cost and effort. In 


\section{WHAT IS ALREADY KNOWN ON THIS TOPIC}

Among people with cardiovascular disease and in the general population, impaired kidney function has been associated with increased risk of cardiovascular disease and all cause mortality

\section{WHAT THIS STUDY ADDS}

Even the earliest stages of chronic kidney disease are associated with higher risk of subsequent coronary heart disease

Assessment of chronic kidney disease in addition to conventional risk factors modestly improves prediction of risk for coronary heart disease

It provides about half as much predictive gain as does history of diabetes or about a sixth as much as does history of smoking
RC, and TA did the statistical analysis. JD and VG supervised the study. EDA and JD are the guarantors.

Funding: This work is underpinned by a programme grant from the British Heart Foundation. RC is supported by a Gates Cambridge PhD scholarship. The sponsors had no role in the design and conduct of the study; collection, management, analysis, and interpretation of the data; or preparation, review, or approval of the manuscript.

Competing interests: All authors have completed the Unified Competing Interest form at www.icmje.org/coi_disclosure.pdf (available on request from the corresponding author) and declare that (1) they have not received any support for the submitted work; (2) they have no relationships with companies that might have an interest in the submitted work in the previous 3 years; (3) their spouses, partners, or children have no financial relationships that may be relevant to the submitted work; and (4) they have no non-financial interests that may be relevant to the submitted work.

Ethical approval: The National Bioethics Committee and the Data Protection Authority of Iceland approved the study protocol, and participants gave informed consent.

Data sharing: No additional data available.

particular, populations with different profiles of prevalence of chronic kidney disease and other risk factors might yield different results for the incremental predictive value of information on chronic kidney disease status.

\section{Strengths and limitations}

We identified participants in population registers, achieved high response and follow-up rates, and used standard methods to assay serum creatinine. Nevertheless, our study had potential limitations. Our participants were of northern European descent, so the findings may not apply to other races. Although we used standard prediction equations to estimate glomerular filtration rate, they were originally developed in patients with kidney disease. ${ }^{31}$ We used qualitative urinary dipstick methods routinely used in clinical practice, but quantitative methods should be more sensitive. ${ }^{32}$ We did not have serial measurements on creatinine concentration or urinary protein. Although sensitivity analyses suggest that our results would be little affected by plausible rates of new onset chronic kidney disease, lack of correction for within person variability could have resulted in bias. Although we used robust methods to ascertain disease outcomes, ${ }^{22}$ preferential diagnoses in people known to have chronic kidney disease may have resulted in overestimation of hazard ratios. By contrast, some random misclassification inherent in using disease registers would have underestimated associations.

\section{Conclusion}

In people without manifest vascular disease, even the earliest stages of chronic kidney disease are associated with excess risk of subsequent coronary heart disease. Assessment of chronic kidney disease in addition to conventional risk factors modestly improves prediction of risk for coronary heart disease. Further studies are needed to investigate associations between chronic kidney disease and non-vascular mortality from causes other than cancer.

Contributors: EDA and RC contributed equally to this work, as did JD and VG. All authors contributed to the study concept and design. TA and VG were responsible for acquisition of data. All authors were involved in analysis and interpretation of data. EDA and JD drafted the manuscript, and all authors critically revised it for important intellectual content. EDA,
1 Baigent C, Burbury K, Wheeler D. Premature cardiovascular disease in chronic renal failure. Lancet 2000;356:147-52. Rouleau JL, et al. Relation between renal dysfunction and cardiovascular outcomes after myocardial infarction. N Engl J Med 2004;351:1285-95.

3 Smith GL, Lichtman JH, Bracken MB, Shlipak MG, Phillips CO, DiCapua $\mathrm{P}$, et al. Renal impairment and outcomes in heart failure: systematic review and meta-analysis. J Am Coll Cardiol 2006;47:1987-96.

4 Rahman M, Pressel S, Davis BR, Nwachuku C, Wright JT Jr, Whelton PK, et al. Cardiovascular outcomes in high-risk hypertensive patients stratified by baseline glomerular filtration rate. Ann Intern Med 2006;144:172-80.

5 Sarnak MJ, Levey AS, Schoolwerth AC, Coresh J, Culleton B, Hamm LL, et al. Kidney disease as a risk factor for development of cardiovascular disease: a statement from the American Heart Association Councils on Kidney in Cardiovascular Disease, High Blood Pressure Research, Clinical Cardiology, and Epidemiology and Prevention. Circulation 2003;108:2154-69.

6 Brosius FC III, Hostetter TH, Kelepouris E, Mitsnefes MM, Moe SM, Moore MA, et al. Detection of chronic kidney disease in patients with or at increased risk of cardiovascular disease: a science advisory from the American Heart Association Kidney and Cardiovascular Disease Council; the Councils on High Blood Pressure Research, Cardiovascular Disease in the Young, and Epidemiology and Prevention; and the Quality of Care and Outcomes Research Interdisciplinary Working Group: developed in collaboration with the National Kidney Foundation. Circulation 2006;114:1083-7.

7 Coresh J, Selvin E, Stevens LA, Manzi J, Kusek JW, Eggers P, et al. Prevalence of chronic kidney disease in the United States. JAMA 2007;298:2038-47.

8 Go AS, Chertow GM, Fan D, McCulloch CE, Hsu CY. Chronic kidney disease and the risks of death, cardiovascular events, and hospitalization. N Engl J Med 2004;351:1296-305.

9 Brugts II, Knetsch AM, Mattace-Raso FUS, Hofman A, Witteman JCM. Renal function and risk of myocardial infarction in an elderly population: the Rotterdam study. Arch Intern Med 2005;165:2659-65.

10 Meisinger C, Doring A, Lowel H, for the KORA Study Group. Chronic kidney disease and risk of incident myocardial infarction and allcause and cardiovascular disease mortality in middle-aged men and women from the general population. Eur Heart / 2006; 27:1245-50.

11 Van Biesen W, De Bacquer D, Verbeke F, Delanghe J, Lameire N, Vanholder R. The glomerular filtration rate in an apparently healthy population and its relation with cardiovascular mortality during 10 years. Eur Heart J 2007;28:478-83

12 Hallan S, Astor B, Romundstad S, Aasarod K, Kvenild K, Coresh J. Association of kidney function and albuminuria with cardiovascula mortality in older vs younger individuals: the HUNT II study. Arch Intern Med 2007;167:2490-6.

13 Kurth T, Jong PED, Cook NR, Buring JE, Ridker PM. Kidney function an risk of cardiovascular disease and mortality in women: a prospective cohort study. BMJ 2009;338:b2392.

14 Hemmelgarn BR, Manns BJ, Lloyd A, James MT, Klarenbach S, Quinn RR, et al. Relation between kidney function, proteinuria, and adverse outcomes. JAMA 2010;303:423-9.

15 Chronic Kidney Disease Prognosis Consortium, Matsushita K, Astor BC, Woodward M, Levey AS, de Jong PE, et al. Association of estimated glomerular filtration rate and albuminuria with all-cause
2 Anavekar NS, McMurray JJV, Velazquez EJ, Solomon SD, Kober L, 
and cardiovascular mortality in general population cohorts: a collaborative meta-analysis. Lancet 2010;375:2073-81.

16 Department of Health. Putting prevention first: vascular checks risk assessment and management. Department of Health, 2008.

17 Jonsdottir LS, Sigfusson N, Gunason V, Sigvaldason H, Thorgeirsson G. Do lipids, blood pressure, diabetes, and smoking confer equal risk of myocardial infarction in women as in men? The Reykjavik study. J Cardiovasc Risk 2002;9:67-76.

18 Viktorsdottir O, Palsson R, Andresdottir MB, Aspelund T, Gudnason V, Indridason OS. Prevalence of chronic kidney disease based on estimated glomerular filtration rate and proteinuria in Icelandic adults. Nephrol Dial Transplant 2005;20:1799-807.

19 Levey A, Greene T, Kusek J, Beck G. A simplified equation to predict glomerular filtration rate from serum creatinine [abstract]. J Am Soc Nephrol 2000;11:155A.

20 Levey AS, Stevens LA, Schmid CH, Zhang Y, Castro AF III, Feldman HI, et al. A new equation to estimate glomerular filtration rate. Ann Intern Med 2009;150:604-12.

21 Danesh J, Wheeler JG, Hirschfield GM, Eda S, Eiriksdottir G, Rumley A, et al. C-reactive protein and other circulating markers of inflammation in the prediction of coronary heart disease. $N$ Engl Med 2004;350:1387-97.

22 Jonsdottir LS, Sigfusson N, Sigvaldason H, Thorgeirsson G. Incidence and prevalence of recognised and unrecognised myocardial infarction in women. Eur Heart J 1998;19:1011-8.

23 Di Angelantonio E, Danesh J, Eiriksdottir G, Gudnason V. Renal function and risk of coronary heart disease in general populations: new prospective study and systematic review. PLoS Med 2007;4:1497-507.
24 Crowe E, Halpin D, Stevens P, on behalf of the Guideline Development Group. Early identification and management of chronic kidney disease: summary of NICE guidance. BMJ 2008;337:812-5.

25 Levey AS, Coresh J, Balk E, Kausz AT, Levin A, Steffes MW, et al. National Kidney Foundation practice guidelines for chronic kidney disease: evaluation, classification, and stratification. Ann Intern Med 2003;139:137-47.

26 Easton D, Peto J, Babiker A. Floating absolute risk: an alternative to relative risk in survival and case-control analysis avoiding an arbitrary reference group. Stat Med 1991;10:1025-35.

27 Steyerberg EW, Vickers AJ, Cook NR, Gerds T, Gonen M, Obuchowski N, et al. Assessing the performance of prediction models: a framework for traditional and novel measures. Epidemiology 2010;21:128-38.

28 Pintilie M. Analysing and interpreting competing risk data. Stat Med 2007;26:1360-7.

29 Emerging Risk Factors Collaboration. Diabetes mellitus, fasting blood glucose concentration, and risk of vascular disease: a collaborative meta-analysis of 102 prospective studies. Lancet 2010;375:2215-22

30 Hage FG, Venkataraman R, Zoghbi GJ, Perry GJ, DeMattos AM, Iskandrian AE. The scope of coronary heart disease in patients with chronic kidney disease. J Am Coll Cardiol 2009;53:2129-40.

31 Verhave JC, Gansevoort RT, Hillege HL, de Zeeuw D, Curhan GC, de Jong PE. Drawbacks of the use of indirect estimates of renal function to evaluate the effect of risk factors on renal function. J Am Soc Nephrol 2004;15:1316-22.

32 Lamb EJ, MacKenzie F, Stevens PE. How should proteinuria be detected and measured? Ann Clin Biochem 2009;46:205-17.

Accepted: 16 August 2010 